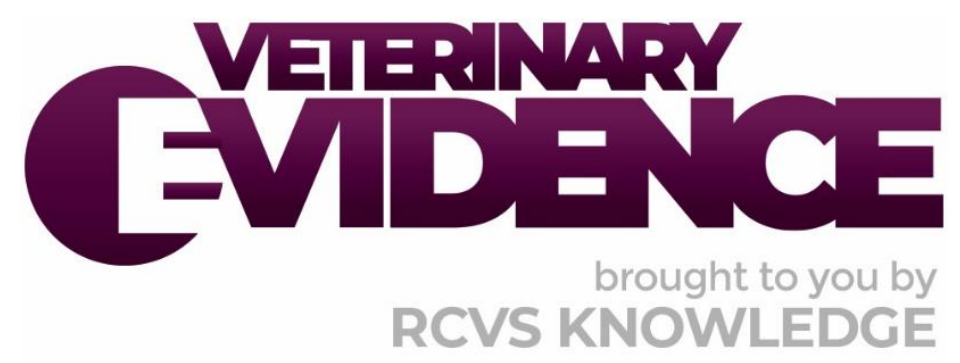

\title{
Diagnostic accuracy of cytology for canine osteosarcoma compared to histopathology
}

A Knowledge Summary by

loannis L. Oikonomidis DVM PhD AFHEA MRCVS ${ }^{1^{*}}$

Theodora K. Tsouloufi DVM PhD AFHEA MRCVS ${ }^{1}$

${ }^{1}$ The Royal (Dick) School of Veterinary Studies, University of Edinburgh, EH25 9RG, UK
${ }^{*}$ Corresponding Author (ioannis.oikonomidis@ed.ac.uk)

ISSN: 2396-9776

Published: 16 Apr 2021

in: The Veterinary Evidence journal Vol 6, Issue 2

DOI: 10.18849/VE.V6I2.399

Reviewed by: Panayiotis Loukopoulos (DVM PGDipVSt PhD) and Chris Thomson (DVM)

Next Review Date: 11 Jun 2022

\section{OPEN
ACCESS $\quad \begin{aligned} & \text { PEER } \\ & \text { REVIEWED }\end{aligned} 23$}




\section{KNOWLEDGE SUMMARY}

\section{PICO question}

What is the sensitivity and specificity of cytology as a test for canine osteosarcoma when compared to histopathology as a gold standard?

\section{Clinical bottom line}

\section{Category of research question}

\section{Diagnosis}

\section{The number and type of study designs reviewed}

Overall, four diagnostic validity studies (two prospective and two retrospective) were critically appraised

\section{Strength of evidence}

Weak to moderate

\section{Outcomes reported}

There is evidence of moderate strength to support that cytology is highly sensitive and specific for diagnosing histologically confirmed osteosarcomas as mesenchymal malignant neoplasms (cytological diagnosis of sarcoma). Evidence of weak strength suggests that the sensitivity and specificity of cytology for identifying the exact histotype (cytological diagnosis of osteosarcoma) are low and high, respectively. Finally, there is currently evidence of weak strength indicating that the sensitivity and specificity of cytology are comparable to that of preoperative histopathology after incisional biopsy for the diagnosis of canine osteosarcoma

\section{Conclusion}

Based on the available evidence, the diagnostic accuracy of cytology in diagnosing histologically confirmed osteosarcomas as sarcomas is high, whereas a confident conclusion cannot be drawn regarding the diagnostic accuracy of cytology for the identification of the exact histotype (cytological diagnosis of osteosarcoma). There is currently scant evidence suggesting that cytology has comparable diagnostic accuracy to preoperative histopathology (i.e. after incisional biopsy) for the diagnosis of canine osteosarcomas, however, more studies are warranted to confirm these results

\section{How to apply this evidence in practice}

The application of evidence into practice should take into account multiple factors, not limited to: individual clinical expertise, patient's circumstances and owners' values, country, location or clinic where you work, the individual case in front of you, the availability of therapies and resources.

Knowledge Summaries are a resource to help reinforce or inform decision making. They do not override the responsibility or judgement of the practitioner to do what is best for the animal in their care. 


\section{The evidence}

The available evidence consists of two prospective studies, one retrospective study in which the cytological and histopathological samples were retrieved and re-examined, and one retrospective study in which the initial cytological and histopathological diagnoses were utilised. Only the two retrospective studies investigated the diagnostic accuracy of cytology for providing a specific diagnosis of osteosarcoma and overall the sensitivity was low, while the specificity (reported only in one of the studies) was high; therefore, the evidence might be considered of weak strength and thus, clear recommendations cannot be made at this stage. On the other hand, cytology appears to be highly sensitive and specific for identifying malignancy (i.e. a generic cytological diagnosis of sarcoma); however, the current evidence should be considered of moderate strength, mostly due to the reported high prevalence of osteosarcoma that has probably induced a positive bias for the specificity. Importantly, the sensitivity and specificity of cytology was comparable to that of preoperative histopathology after incisional biopsy; however, the current evidence is based on a single study and should therefore, be considered weak overall.

\section{Summary of the evidence}

\begin{tabular}{|c|c|}
\hline \multicolumn{2}{|l|}{ Loukopoulos et al. (2005) } \\
\hline Population: & Dogs with histologically confirmed osteosarcomas \\
\hline Sample size: & 27 dogs \\
\hline Intervention details: & $\begin{array}{l}\text { - Preoperative cytological examination was performed, but no } \\
\text { further details for the procedure are available. } \\
\text { - Histopathological examination was performed, but no } \\
\text { further information is available regarding the procedure. }\end{array}$ \\
\hline Study design: & Diagnostic validity retrospective study \\
\hline Outcome studied: & $\begin{array}{l}\text { Sensitivity of cytology for the diagnosis of canine osteosarcoma } \\
\text { using histopathology as a gold standard }\end{array}$ \\
\hline $\begin{array}{l}\text { Main findings: } \\
\text { (relevant to PICO question): }\end{array}$ & $\begin{array}{l}\text { - In } 3 / 27 \text { ( } 11.1 \%) \text { cases, the cytological diagnosis was not } \\
\text { specific or was inconclusive. } \\
\text { - In } 6 / 27(22.2 \%) \text { cases, the cytological diagnosis was in full } \\
\text { agreement with the histopathology. } \\
\text { - In } 13 / 27 \text { ( } 48.1 \%) \text { cases, the cytological diagnosis was in } \\
\text { partial agreement with the histopathology (cytological } \\
\text { diagnosis of malignant neoplasia). } \\
\text { - In } 5 / 27 \text { ( } 18.5 \%) \text { cases, the cytological diagnosis was not in } \\
\text { agreement with the histopathology. } \\
\text { - Therefore, the sensitivity of cytology for identifying the } \\
\text { malignancy was } 70.3 \% \text {, while for determining the exact } \\
\text { histotype was } 22.2 \% \text {. } \\
\text { - After excluding the non-diagnostic specimens from the } \\
\text { analysis, the sensitivity of cytology for diagnosing the } \\
\text { malignancy and exact histotype was } 79.2 \% \text { and } 25.0 \% \text {, } \\
\text { respectively. }\end{array}$ \\
\hline Limitations: & $\begin{array}{l}\text { The authors retrospectively identified the cases to be } \\
\text { included, but they did not retrieve the samples to re- } \\
\text { examine them. They relied on the initial cytological and } \\
\text { histopathological diagnoses made by different pathologists. }\end{array}$ \\
\hline
\end{tabular}




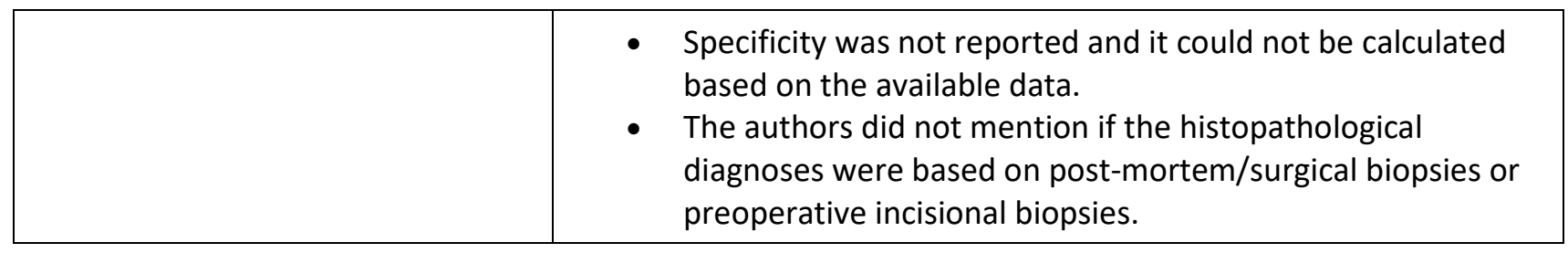

\begin{tabular}{|c|c|}
\hline \multicolumn{2}{|l|}{ Britt et al. (2007) } \\
\hline Population: & Dogs with aggressive appendicular bone lesions \\
\hline Sample size: & 36 dogs \\
\hline Intervention details: & $\begin{array}{l}\text { - Fine needle aspiration (FNA) cytological examination was } \\
\text { performed using a } 20 \text { gauge needle and a } 12 \mathrm{~mL} \text { syringe. The } \\
\text { smears were stained with Wright-Giemsa. } \\
\text { - Histopathological examination was performed after } \\
\text { preoperative incisional or surgical excisional biopsy. }\end{array}$ \\
\hline Study design: & Diagnostic validity prospective study \\
\hline Outcome studied: & $\begin{array}{l}\text { Sensitivity and specificity of FNA cytology for the diagnosis of canine } \\
\text { osteosarcoma using histopathology as a gold standard }\end{array}$ \\
\hline $\begin{array}{l}\text { Main findings: } \\
\text { (relevant to PICO question): }\end{array}$ & $\begin{array}{l}\text { - } \quad \text { 4/36 (11.1\%) specimens were non-diagnostic. } \\
\text { osteosarcomas histologically. } 2 / 32 \text { samples were diagnosed } \\
\text { as reactive bone histologically. } \\
\text { - Cytology classified } 29 / 30 \text { histologically confirmed } \\
\text { osteosarcomas as sarcomas. One of them was diagnosed as } \\
\text { reactive bone. Further classification into a specific histotype } \\
\text { was not possible. } \\
\text { - The sensitivity of cytology for identifying osteosarcomas as } \\
\text { sarcomas was } 85.3 \% \text { or } 96.7 \% \text {, after excluding the non- } \\
\text { diagnostic specimens from the analysis. } \\
\text { - The specificity was } 100 \% \text {. }\end{array}$ \\
\hline Limitations: & $\begin{array}{l}\text { - The prevalence of osteosarcoma was very high in this study, } \\
\text { inducing inevitably a positive bias in the calculation of } \\
\text { specificity. } \\
\text { - The authors provided a diagnosis of sarcoma cytologically } \\
\text { without attempting to specify the exact histotype. }\end{array}$ \\
\hline
\end{tabular}

Neihaus et al. (2011)

\begin{tabular}{|r|r|}
\hline Population: & Dogs with lytic and/or proliferative bone lesions \\
\hline Sample size: & 27 dogs \\
\hline Intervention details: & $\begin{array}{r}\text { FNA cytological examination was performed using a } 22 \\
\text { gauge needle and a } 6 \mathrm{~mL} \text { syringe. The smears were stained } \\
\text { with Wright-Giemsa. }\end{array}$ \\
& $\begin{array}{l}\text { Core aspirate (CA) cytological examination was performed } \\
\text { using a } 16 \text { gauge bone marrow biopsy needle. The smears } \\
\text { were stained with Wright-Giemsa. }\end{array}$ \\
\hline
\end{tabular}




\begin{tabular}{|c|c|}
\hline & $\begin{array}{l}\text { - Histopathological examination was performed after an } \\
\text { incisional biopsy using Jamshidi } i^{\mathrm{TM}} \text { needle. The sections were } \\
\text { stained with haematoxylin and eosin. }\end{array}$ \\
\hline Study design: & Diagnostic validity prospective study \\
\hline Outcome studied: & $\begin{array}{l}\text { Sensitivity and specificity of FNA and CA cytology for the diagnosis of } \\
\text { osteosarcoma using histopathology as a gold standard }\end{array}$ \\
\hline $\begin{array}{l}\text { Main findings: } \\
\text { (relevant to PICO question): }\end{array}$ & $\begin{array}{l}\text { - } 20 / 27 \text { cases were diagnosed as osteosarcomas histologically. } \\
\text { - FNA cytology identified } 17 / 20 \text { histologically confirmed } \\
\text { osteosarcomas as sarcomas. } \\
\text { - CA cytology identified } 19 / 20 \text { histologically confirmed } \\
\text { osteosarcomas as sarcomas. } \\
\text { - All missed cases ( } 3 / 20 \text { using FNA cytology and } 1 / 20 \text { using CA } \\
\text { cytology) were diagnosed as reactive bone. } \\
\text { - The sensitivity of FNA and CA cytology for identifying } \\
\text { osteosarcomas as sarcomas was } 85.0 \% \text { and } 95.0 \% \text {, } \\
\text { respectively. }\end{array}$ \\
\hline Limitations: & $\begin{array}{l}\text { - The prevalence of osteosarcoma was very high in this study, } \\
\text { inducing inevitably a positive bias in the calculation of } \\
\text { specificity. } \\
\text { - The authors provided a diagnosis of sarcoma cytologically } \\
\text { without attempting to specify the exact histotype. }\end{array}$ \\
\hline
\end{tabular}

Sabattini et al. (2017)

\begin{tabular}{|c|c|}
\hline Population: & Dogs with bone lesions \\
\hline Sample size: & 68 dogs with bone lesions, 40 dogs with osteosarcomas \\
\hline Intervention details: & $\begin{array}{l}\text { - FNA cytological examination was performed using } 21-22 \\
\text { gauge needle and } 2.5-5.0 \mathrm{~mL} \text { syringe. The smears were } \\
\text { stained with May-Grünwald-Giemsa. } \\
\text { - Histopathological examination was performed after } \\
\text { preoperative incisional biopsy using 8-11 gauge Jamshidi } \\
\text { needle. The sections were stained with haematoxylin and } \\
\text { eosin. } \\
\text { - Histopathological examination was performed after surgical } \\
\text { excisional biopsy or post-mortem examination. The sections } \\
\text { were stained with haematoxylin and eosin. }\end{array}$ \\
\hline Study design: & Diagnostic validity retrospective study \\
\hline Outcome studied: & $\begin{array}{l}\text { Sensitivity and specificity of FNA cytology and preoperative } \\
\text { histopathology for the diagnosis of osteosarcoma using surgical or } \\
\text { post-mortem histopathology as a gold standard }\end{array}$ \\
\hline $\begin{array}{l}\text { Main findings: } \\
\text { (relevant to PICO question): }\end{array}$ & $\begin{array}{l}\text { - In 5/40 histologically confirmed osteosarcomas, cytological } \\
\text { examination was not performed. } \\
\text { - FNA cytology identified correctly } 15 / 35(42.9 \%) \\
\text { osteosarcomas. }\end{array}$ \\
\hline
\end{tabular}




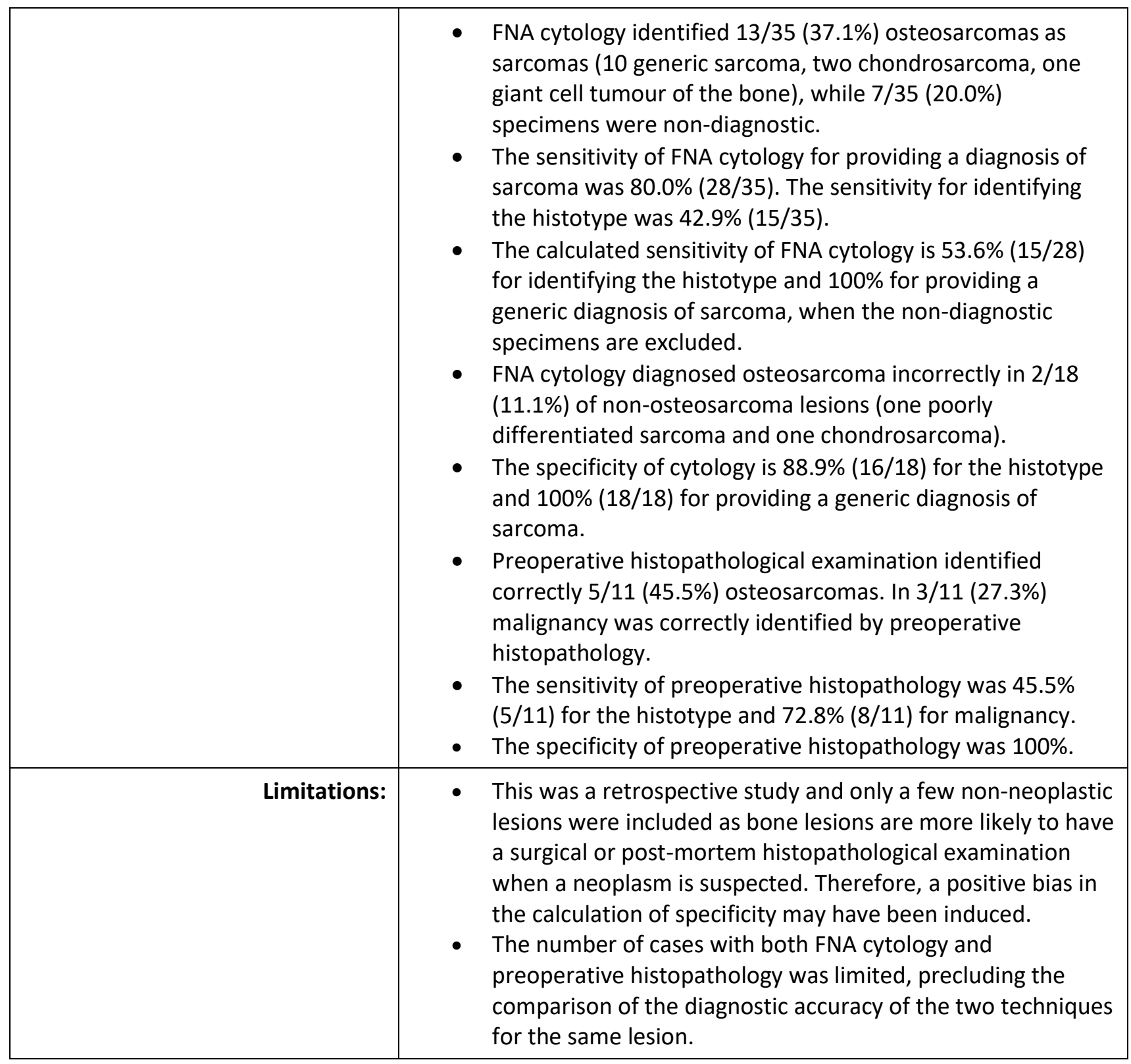

\section{Appraisal, application and reflection}

Moderately strong evidence indicates that cytology is highly sensitive and specific for diagnosing histologicallyconfirmed osteosarcomas as sarcomas. There is weak evidence suggesting that the sensitivity and specificity of cytology for identifying the exact histotype (i.e. osteosarcoma) are low and high, respectively. Finally, weak evidence suggests that the sensitivity and specificity of cytology and preoperative histopathology after incisional biopsy are comparable for the diagnosis of canine osteosarcoma.

Malignant bone tumours are relatively common in dogs. Specifically, according to two studies performed in the USA, they account for 2-7\% of all malignant neoplasias in dogs, ${ }^{1,2}$ while in one epidemiological European study, the incidence rate of malignant bone tumours was 5.5 cases per 10,000 dog-years at risk. ${ }^{3}$ Osteosarcoma is by far the most common malignant bone neoplasm, accounting for up to $85 \%$ of primary skeletal malignant neoplasms. ${ }^{4}$ The clinicians often rely on signalment, history, clinical findings, and radiographical abnormalities to make a presumptive diagnosis of a malignant bone tumour. However, benign disorders (e.g. osteomyelitis) may exhibit similar clinical and radiographical features with malignancies, thus complicating the differential diagnosis. Moreover, the surgical approach, the prognosis and further postsurgery therapeutic interventions might differ substantially between the different types of primary bone 
malignancies. Specifically, osteosarcoma is considered a highly malignant neoplasm with a low median survival time and high metastatic potential, while adjuvant chemotherapy may also be required to prolong the survival time in these cases. ${ }^{5}$

Incisional biopsy and histopathological examination is often recommended prior to surgery and is considered the gold standard for the diagnosis of primary bone lesions. However, several technique related complications, such as pathological fractures, haematomas, or even local seeding of neoplastic cells have been reported with bone biopsy. ${ }^{6}$ Moreover, the procedure requires the induction of general anaesthesia and is reportedly associated with enhanced patient pain. ${ }^{6}$ Fine needle aspiration (FNA) cytology is a cost-effective and less invasive alternative to preoperative histopathology, which is typically associated with minimal complications, and is characterised by a very short turnaround time. ${ }^{7}$

Overall, four studies met the inclusion criteria for critical appraisal. The sensitivity of cytology for diagnosing histologically-confirmed osteosarcomas as sarcomas was high, ranging from $79.2 \%$ to $95.0 \%$, and its specificity was $100 \%$ in three out of four studies. ${ }^{4,8-10}$ The sensitivity of cytology in identifying the exact histotype (i.e. providing a specific diagnosis of osteosarcoma rather than a generic diagnosis of sarcoma) was investigated only by Loukopoulos et al. (2005) and Sabattini et al. (2017), and it was found to be lower $(25.0 \%$ and $42.9 \%$, respectively). ${ }^{4,11}$ Conversely, the specificity was only reported by Sabattini et al. (2017) and found to be quite high (88.9\%). ${ }^{4}$ Interestingly, Sabattini et al. (2017) compared the diagnostic accuracy of FNA cytology and preoperative histopathology after incisional biopsy with that of histopathology after surgical excisional biopsy or post-mortem examination as a gold standard. Surprisingly, the sensitivity of preoperative histopathology was lower than that of FNA cytology (45.5\% vs $53.6 \%$ for histotype and $72.8 \%$ vs $100 \%$ for malignancy). ${ }^{4}$ This could be explained by some inherent limitations of the incisional biopsy as a technique to obtain bone samples, namely limited available tissue for evaluation due to small sample size, presence of artifacts (e.g. crush artifact, artifactual changes due to decalcification), or non-representative specimen (e.g. sampling of necrotic areas or surrounding reactive bone). This finding could be of clinical relevance as cytology is minimally invasive when compared to preoperative biopsy; however, more studies are warranted in order to support this study's findings. Furthermore, in most of the above studies, cytology was associated with a rate of nondiagnostic specimens, ranging from $11.1 \%$ to $20.0 \%,{ }^{4,8,11}$ which highlights an inherent limitation of this diagnostic test.

Even though the sensitivity of cytology for providing a specific diagnosis of osteosarcoma appears to be low, its high sensitivity and specificity for identifying histologically confirmed osteosarcomas as sarcomas is equally important for routine purposes. Specifically, the cytological examination can be easily complemented with the use of a special stain for alkaline phosphatase (ALP) activity, which was found to be highly sensitive (88-100\%) and specific (89-94\%) for diagnosing canine osteosarcomas. ${ }^{10,12}$ Importantly, this special staining is a simple and rapid test that can be performed on previously stained cytological slides. ${ }^{12}$ The main disadvantage of ALP staining remains the lack of specificity for malignant osteoblasts, as all osteoblasts normally express this enzyme. ${ }^{10}$

All the appraised studies are diagnostic validity studies and are therefore, placed high in the evidence hierarchy; nonetheless, several limitations are recognised in them. Specifically, given that the calculated accuracy of a diagnostic test is heavily dependent on the prevalence of the target condition, the reported diagnostic accuracy, and especially the specificity, appears to be somewhat biased at least in the studies of Britt at al. (2007) and Neihaus et al. (2011), ${ }^{8,9}$ as only rare cases with a diagnosis of non-osteosarcoma were included. Moreover, in the aforementioned studies, the authors merely provided a cytological diagnosis of sarcoma without defining the exact histotype of the tumour, which thus, precludes the determination of diagnostic accuracy of cytology for providing a specific diagnosis of osteosarcoma. Finally, in the study of Sabattini et al. (2017), which was the only one that compared the diagnostic accuracy of cytology to that of preoperative histopathology, a low number of cases were subject to both tests, therefore, a direct comparison of these two tests on the same lesions was limited.

In conclusion, there is evidence of moderate strength suggesting that cytology is highly sensitive and specific for providing a diagnosis of sarcoma in cases of histologically confirmed canine osteosarcomas. In terms of identifying the exact histotype (i.e. providing a specific diagnosis of osteosarcoma), the current evidence should be considered overall weak and as such, no definitive conclusions can be drawn at this stage. Nonetheless, cytology seems to lack adequate sensitivity for the diagnosis of canine osteosarcomas, but it 
seems to be highly specific, which is useful for excluding this type of neoplasm. Surprisingly, the currently available evidence suggests that the diagnostic accuracy of preoperative histopathology seems not be superior to that of FNA cytology for the diagnosis of osteosarcomas, although the former should be considered of weak strength and thus, does not allow definitive conclusions to be drawn. However, an inherent limitation of bone cytology is related to the rate of non-diagnostic specimens, which appears to be relatively low, but it should be taken into consideration and properly communicated to the owner. Prospective studies focusing on the diagnostic performance of cytology as compared to that of preoperative histopathology are warranted, in order to provide solid evidence on the use of the two techniques for the diagnosis of canine osteosarcomas prior to surgery.

\section{Methodology Section}

\begin{tabular}{|c|c|}
\hline \multicolumn{2}{|l|}{ Search Strategy } \\
\hline $\begin{array}{r}\text { Databases searched and dates } \\
\text { covered: }\end{array}$ & $\begin{array}{l}\text { CAB Abstracts on the OVID interface 1973-2020, week } 22 \\
\text { PubMed accessed via the NCBI website 1920-June } 2020\end{array}$ \\
\hline Search terms: & 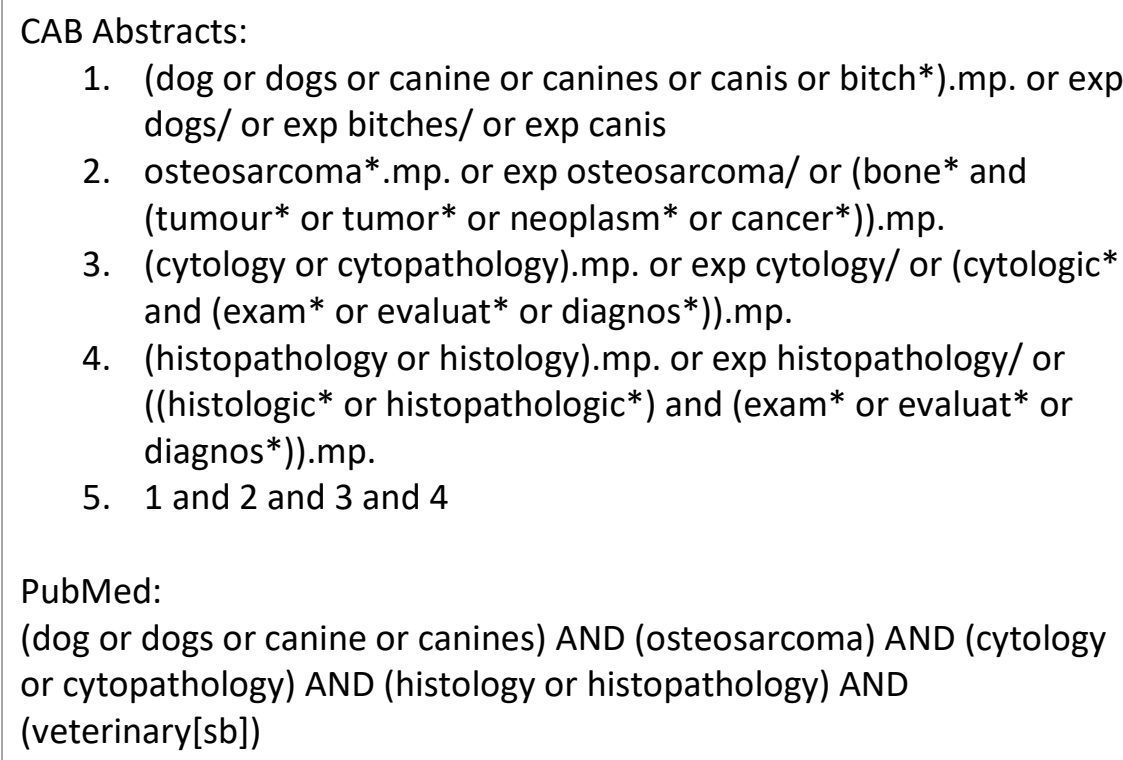 \\
\hline Dates searches performed: & 11 Jun 2020 \\
\hline
\end{tabular}

\section{Exclusion / Inclusion Criteria}

For the present Knowledge Summary, only original research articles were considered for inclusion, as the aim was to investigate measures of test performance (i.e. quantitative data) and thus, sources of qualitative evidence (i.e. expert opinion articles, narrative reviews) were excluded even if relevant. Conference abstracts were excluded as they were not likely to provide the level of detail needed for the appraisal of the evidence.

Exclusion:
- Studies investigating species other than dogs/other bone neoplasms

- Case reports

- Non-peer reviewed literature (e.g. conference abstracts, theses, expert opinion articles)

- Narrative reviews

- Studies not written in English

- Studies not available as full texts 
- Original research articles

- Studies investigating the diagnostic accuracy of cytology either alone or in comparison to histopathology

- Studies written in English

\begin{tabular}{|c|c|c|c|c|c|c|c|}
\hline \multicolumn{8}{|c|}{ Search Outcome } \\
\hline Database & $\begin{array}{l}\text { Number } \\
\text { of } \\
\text { results }\end{array}$ & $\begin{array}{l}\text { Excluded - } \\
\text { Not } \\
\text { relevant } \\
\text { to PICO } \\
\text { question }\end{array}$ & $\begin{array}{l}\text { Excluded - } \\
\text { Case } \\
\text { report }\end{array}$ & $\begin{array}{c}\text { Excluded - } \\
\text { Review } \\
\text { article }\end{array}$ & $\begin{array}{c}\text { Excluded - } \\
\text { Conference } \\
\text { abstract }\end{array}$ & $\begin{array}{l}\text { Excluded - } \\
\text { Not English- } \\
\text { written } \\
\text { study }\end{array}$ & $\begin{array}{c}\text { Total } \\
\text { relevant } \\
\text { papers }\end{array}$ \\
\hline $\begin{array}{l}\text { CAB } \\
\text { Abstracts }\end{array}$ & 143 & 113 & 17 & 4 & 2 & 3 & 4 \\
\hline PubMed & 527 & 449 & 68 & 6 & 0 & 0 & 4 \\
\hline \multicolumn{7}{|c|}{ Total relevant papers when duplicates removed } & 4 \\
\hline
\end{tabular}

\section{CONFLICT OF INTEREST}

The authors declare no conflict of interest.

\section{REFERENCES}

1. Priester, W.A. \& McKay, F.W. (1980). The occurrence of tumors in domestic animals. National Cancer Institute Monograph. 1-210.

2. Dom, C.R., Taylor, D.O.N., Schneider, R., Hibbard, H.H. \& Klauber, M.R. (1968). Survey of Animal Neoplasms in Alameda and Contra Costa Counties, California. II. Cancer Morbidity in Dogs and Cats From Alameda County. Journal of the National Cancer Institute. 40, 307-318.

DOI: https://doi.org/10.1093/jnci/40.2.307

3. Egenvall, A., Nødtvedt, A. \& von Euler, H. (2007). Bone tumors in a population of 400000 insured Swedish dogs up to 10 y of age: incidence and survival. Canadian Journal of Veterinary Research. 71(4), 292-299.

4. Sabattini, S., Renzi, A., Buracco, P., Defourny, S., Garnier-Moiroux, M., Capitani, O. \& Bettini, G. (2017). Comparative Assessment of the Accuracy of Cytological and Histologic Biopsies in the Diagnosis of Canine Bone Lesions. Journal of Veterinary Internal Medicine. 31(3), 864-871.

DOI: https://doi.org/10.1111/ivim.14696 
5. Thompson, K.G. \& Dittmer, K.E. (2017). Tumors of Bone. In: Meuten DJ, ed. Tumors in Domestic Animals, 5th ed. Ames, lowa, USA: Wiley Blackwell; 356-424.

6. Mankin, H.J., Mankin, C.J. \& Simon, M.A. (1996). The Hazards of the Biopsy, Revisited. For the Members of the Musculoskeletal Tumor Society*. The Journal of Bone \& Joint Surgery. 78(5), 656-663. DOI: https://doi.org/10.2106/00004623-199605000-00004

7. Sharkey, L.C., Dial, S.M. \& Matz, M.E. (2007). Maximizing the Diagnostic Value of Cytology in Small Animal Practice. Veterinary Clinics of North America: Small Animal Practice. 37(2), 351-372. DOI: https://doi.org/10.1016/j.cvsm.2006.11.004

8. Britt, T., Clifford, C., Barger, A., Moroff, S., Drobatz, K., Thacher, C. \& Davis, G. (2007). Diagnosing appendicular osteosarcoma with ultrasound-guided fine-needle aspiration: 36 cases. Journal of Small Animal Practice. 48, 145-150. DOI: https://doi.org/10.1111/j.1748-5827.2006.00243.x

9. Neihaus, S.A., Locke, J.E., Barger, A.M., Borst, L.B. \& Goring, R.L. (2011). A Novel Method of Core Aspirate Cytology Compared to Fine-Needle Aspiration for Diagnosing Canine Osteosarcoma. Journal of the American Animal Hospital Association. 47(5), 317-323. DOI: https://doi.org/10.5326/JAAHA-MS$\underline{5676}$

10. Loukopoulos, P., Rozmanec, M. \& Sutton, R.H. (2005). Cytological versus histopathological diagnosis in canine osteosarcoma. Veterinary Record. 157(24), 784-784. DOI: https://doi.org/10.1136/vr.157.24.784

11. Barger, A., Graca, R., Bailey, K., Messick, J., de Lorimier, L-P., Fan, T. \& Hoffman W. (2005). Use of Alkaline Phosphatase Staining to Differentiate Canine Osteosarcoma from Other Vimentin-positive Tumors. Veterinary Pathology. 42(2), 161-165. DOI: https://doi.org/10.1354/vp.42-2-161

12. Ryseff, J.K. \& Bohn, A.A. (2012). Detection of alkaline phosphatase in canine cells previously stained with Wright-Giemsa and its utility in differentiating osteosarcoma from other mesenchymal tumors. Veterinary Clinical Pathology. 41(3), 391-395. DOI: https://doi.org/10.1111/j.1939165X.2012.00445.x 


\section{EVIIDEFeE

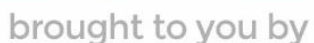 \\ RCVS KNOWLEDGE}

\section{Intellectual Property Rights}

Authors of Knowledge Summaries submitted to RCVS Knowledge for publication will retain copyright in their work, and will be required to grant RCVS Knowledge a non-exclusive license of the rights of copyright in the materials including but not limited to the right to publish, re-

publish, transmit, sell, distribute and otherwise use the materials in all languages and all media throughout the world, and to license or permit others to do so.

\section{Disclaimer}

Knowledge Summaries are a peer-reviewed article type which aims to answer a clinical question based on the best available current evidence. It does not override the responsibility

of the practitioner. Informed decisions should be made by considering such factors as individual clinical expertise and judgement along with patient's circumstances and owners' values. Knowledge Summaries are a resource to help inform and any opinions expressed within the Knowledge Summaries are the author's own and do not necessarily reflect the view of the RCVS Knowledge. Authors are responsible for the accuracy of the content. While the

Editor and Publisher believe that all content herein are in accord with current recommendations and practice at the time of publication, they accept no legal responsibility

for any errors or omissions, and make no warranty, express or implied, with respect to material contained within.

For further information please refer to our Terms of Use.

RCVS Knowledge is the independent charity associated with the Royal College of Veterinary Surgeons (RCVS). Our ambition is to become a global intermediary for evidence based veterinary knowledge by providing access to information

that is of immediate value to practicing veterinary professionals and directly contributes to evidence based clinical decision-making.

https://www.veterinaryevidence.org/

RCVS Knowledge is a registered Charity No. 230886.

Registered as a Company limited by guarantee in England and Wales No. 598443.

Registered Office: Belgravia House, 62-64 Horseferry Road, London SW1P 2AF

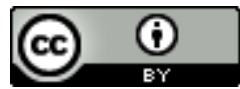

This work is licensed under a Creative Commons Attribution 4.0 International License 